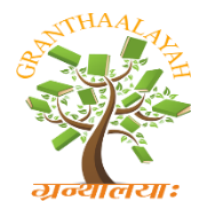

INTERNATIONAL JOURNAL OF RESEARCH GRANTHAALAYAH A knowledge Repository

Science

\title{
PATTERN OF HEALTH CARE EXPENDITURE OF PRIVATE AND PUBLIC: A CASE STUDY OF HOSPITAL PATIENTS IN KANNUR DISTRICT, KERALA, INDIA
}

\author{
Maneesh P ${ }^{* 1}$, Aicha EL ALAOUI ${ }^{2}$ \\ ${ }^{* 1}$ Ph.D., Research Scholar, Department of Econometrics, School of Economics, Madurai \\ Kamaraj University, Madurai, Tamil Nadu, India \\ ${ }^{2}$ Associate Professor, University Sultan My Slimane, BeniMellal, Morocco. Member of \\ Laboratory of Economic and Social Sciences, BeniMellal
}

\begin{abstract}
In Kerala, the disturbing trend is that the public health care system is getting alienated from the people since 1980 's. About $30 \%$ of the lower income families seeks medical service from the government hospitals. This is because of the fall in the quality of the services of the government hospitals. In the present situation, the rate of utilization of the private sector can be increased drastically pointing to the poor performance of the public health care system. The government hospital has some problems like poor physical or infrastructure facilities, ineffective leadership and unsatisfactory supply of drugs and medical supplies faculty of staffing procedure. These above stated problems do not exist in private hospitals. Therefore, the present study carried out to assess the healthcare expenditure of government and private hospitals patients in Kannur district. The study was conducted during 2015-16. The sample size of the survey contains a total of 120 respondents from Kannur district. The study analyses the interrelationship between health care expenditure and major socioeconomic factors such as monthly income, age, gender, marital status and occupation. The health care expenditure divided into two-direct and indirect health care cost. The direct health care cost includes- user fee charge, medical charge, diagnostic charge and surgical cost. The indirect health care cost comprises of transportation charge, food and bevarages charge and accommodation charges. The study found that the direct cost of health care is high in both private and public sector hospitals. Finally, the study suggests that an initiative along the role of government is requested to secure the health demands of poor as health care costs are growing over time.
\end{abstract}

Keywords: Healthcare Expenditure; Private-Public Hospitals; Socio-Economic Condition; Hospital's Performance.

Cite This Article: Maneesh P, and Aicha EL ALAOUI. (2018). "PATTERN OF HEALTH CARE EXPENDITURE OF PRIVATE AND PUBLIC: A CASE STUDY OF HOSPITAL PATIENTS IN KANNUR DISTRICT, KERALA, INDIA." International Journal of Research Granthaalayah, 6(5), 431-449. https://doi.org/10.29121/granthaalayah.v6.i5.2018.1471. 


\section{Introduction}

India is the second largest populated country in the world. Health is an important determinant of wellbeing and health care is regarded as a public right, and an important responsibility of governments is to provide the care to all people irrespective of race, religion, caste or creed, rural or urban, rich or poor, and so on.

The effort to improve the health status of the population is a major thrust and it is under the social development program being undertaken in India. Public health programmes play a very significant role in the physical and mental wellbeing of every nation. The improvement of the health status of people is connected to number of factors such as household income, public expenditure on healthcare delivery system, availability of private healthcare facilities and general environmental conditions affecting incidence of diseases. The health status of the population of a nation was assumed to affect utility of the people directly by the value that individual place on good health and indirectly through increasing healthy time and labour income of the person. The rising of income levels, the households are able to spend on better healthcare, education and nutrition leading to an improvement in health status. The improved health status of the people helps the process of economic development in a positive way. The planning of health in India started as early as in 1943, when the Bhore committee was appointed to go into health and medical needs of India. In the time of independence in 1947, the health infrastructure was mainly urban and clinic based, and it providing curative services only.

The final of the third five year plan, India laid the foundation of basic health care services and the subsequent fiver plans focused on the need to integrate family planning with maternal and child health and nutrition services. The sixth five year plan adopted the goal of "health for all". In 1983 the first National Health Policy (NHP) was announced. In the period of seventh five year plan the major thrust was laid on the consolidation of health infrastructure already developed. The eight five year plan objective is that the health facilities must reach the curative population by the end of the plan period and also the ninth five year plan observed that inappropriate location, poor access, poor maintenance, gaps in critical manpower, mismatch between personnel and equipment, lack of essential drugs, diagnostics, poor referred linkages were some of the factors responsible for sub-optimal functioning of primary health care institutions. Most recently, the ministry of health government of India prepared the National Health Policy 2002, (NHP).

The main objective of NHP 2002 is to achieve an acceptable standard of good health among the general population of the country. The NHP is being worked upon further in 2015 and a draft for public consultation has been release. The primary aim of the NHP 2015 is to inform, clarify, strengthen and prioritize the role of the government in shaping health systems in all its dimensions investment in health organization and financing of health care services, prevention of diseases and promotion of good health through cross sectorial action access to technologies, developing human resources, encouraging medical pluralism, building the knowledge base required for better health, financial protection strategies and regulation and legislation for health, (Draft of NHP, 2015).

In India, there is a significantly large public health care sector; the larger provide health sector mostly for curative care completely weakness the former presence. The National Sample Survey Organization (NSSO) data clearly shows a major decline in utilization of the public health care facilities for inpatient care and a corresponding increase in utilization of the same from public 
health providers in both rural and urban areas of the country. Despite the higher cost in the private sector, this shift shows that the people are losing trust in the public health care system. The reason for low utilization of public health care sector appear critical shortage of health personnel, inadequate incentives, poor working conditions, lack of transparency in posting doctors in rural areas, poor outreach, time of services, insensitivity to local needs, inadequate salary, and poor monitoring of services or facilities. The availability of the infrastructure and manpower in terms of quantity is almost a pre-condition for achieving better healthcare services. The basis of the Alma Ata declaration was an acceptance that the most effective way to develop a cost effective and equitable system of healthcare was to focus on the delivery of basic health services.

The health infrastructure in India has a long way to go towards achieving $100 \%$ quality technology and superior health care delivery systems. The private sector provides $80 \%$ of the health care services and only $20 \%$ are provided by the government, (www.buyusa.gov/india). The private health sector predominates in the provisioning of curative services. India's private health sector accounts for about $80 \%$ outpatient treatments for both rich and poor, more than $55 \%$ of all inpatient admissions or hospitalization i.e. curative services, $40 \%$ of prenatal care, $55 \%$ of institutional deliveries and as low as $10 \%$ of immunizations delivered. It provides $40 \%$ of hospitalizations for the poor and $60 \%$ for the privileged, (MukhopadhyayDebes, 2006). The provision of health care services will improve the physical and mental developments of the human being.

In India, the general government (central and state) expenditure on health was only $1.36 \%$ of the GDP in 2012-13 estimates. The public health expenditure represented 1.28\% of GDP as of 2013. Its highest value over the past 18 years was $1.28 \%$ of GDP in 2013, while its lowest value was $1.00 \%$ of GDP in 2005. However, the private health expenditure was $2.69 \%$ of GDP as of 2013. Its highest value over the past 18 years was $3.56 \%$ of GDP in 2004, while its lowest value was $2.65 \%$ of GDP in 2012.

The present study tries to measure the pattern of health care expenditure of private and public in Kerala especially in the Hospital Patients in Kannur District. This district is situated in the northerly part of the Kerala state spread between the Lakshadweep Sea and Western Ghats. The district came into existence as an administrative unit on $1^{\text {st }}$ January 1957, when the erstwhile Malabar district and KasargodTaluk of Madras province were reconstituted into three revenue districts Viz., Kannur, Kozhikode and Palakkad. The district can be classified into three distinctive regions geologically as coastal, midland and forest hilly regions. The total population of the district as per the 2011 census is 2.525 .637 , which $46.9 \%$ are male and $53.1 \%$ are female. The sex ratio is 100 males 113 females. The density of population is 852 persons per square kilometer of land area. The literacy rate in the district is $85.4 \%$. There are 147 private hospitals against 9 government hospitals and 31 private dispensaries against 7 government dispensaries. There are 82 PHC's and $10 \mathrm{CHC}$ 's in the district.

Two main objectives of this study:(1)It is carried to investigate the socio-economic characteristics of the sample respondents in a comparative framework, and (2) it is carried to estimate the health expenditure of the sample respondents. The methodology is presented as follows. The database for this study consists of primary and secondary data. A well-structured schedule was prepared to collect primary data from the study area. Personal interview method is adopted to collect the 
necessary primary data. The sample population for the field survey comprises a total of 120 respondents from Kannur district. The respondents were selected randomly from Kannur municipality. The data collected through schedule method were entered in to the computer using SPSS package and simple $2 \times 2$ tables were prepared. Tabular analysis is carried out. The tools, such as average and per cent age are used in the tabular analysis. The general information and performance of the hospital has been analysed with the help of primary data collected from the respondents through structured schedule. Likewise, the socio-economic and personal condition of the respondents has also been analysed on the basis of primary data. The tools like simple average, per cent age and Chi-square test, Spearman's rank correlation has also been applied.

It important to mention that health spending is largely unpredictable and any significant fraction of household spending on direct payments made for purchasing health care services and drugs commonly called out of pocket payments can cause a disruptive impact on household expenditure and ultimately an impoverishing effect on its existing standard. The expenditure of health is an important factor, which influence the demand for health services. Therefore, the analysis of pattern of expenditure on health care is significant as it defines the affordability of modern health care to various income groups. Following sections examine and discuss results of this study.

\section{Results and Discussions}

\subsection{Health Charges}

Healthcare expenditure cuts poor respondents in two ways. Not only do they have to spend a large amount of money and resources on medical care, but they are also unable to earn during the period of illness. For that, the patients support both direct and indirect charges during the treatment. Those will occur according to the disease status and illness, and when the person comes to the consultation or when he is hospitalized.

\subsubsection{Direct Cost of Healthcare}

Direct costs covered various charges directly related to the healthcare. They included user fee charges, diagnostic charge, medicine charge and surgical charge. The results of this study for the direct cost are presented as follows.

\section{- User Fee Charges}

Patients pay user fee for the use of healthcare facilities. In health economics, user fee refers to a system of charges for basic health care services. However, in government hospital there is no user fee as the healthcare services are provided free of charge to the patients. While the private healthcare services, charge user fee for looking after the patients, Table 1. The user fee generally varies according to the disease status, illness, injury and treatment; these are referred as the costs of health services. 
Table 1: User fee charges

\begin{tabular}{|l|l|l|l|}
\hline Amount (Rs) & Government hospital & Private hospital & Total \\
\hline Below 100 & - & 15 & 15 \\
\hline $\mathbf{1 0 1 - 2 0 0}$ & - & 39 & 39 \\
\hline Above 200 & - & 1 & 1 \\
\hline Total & - & 55 & 55 \\
\hline
\end{tabular}

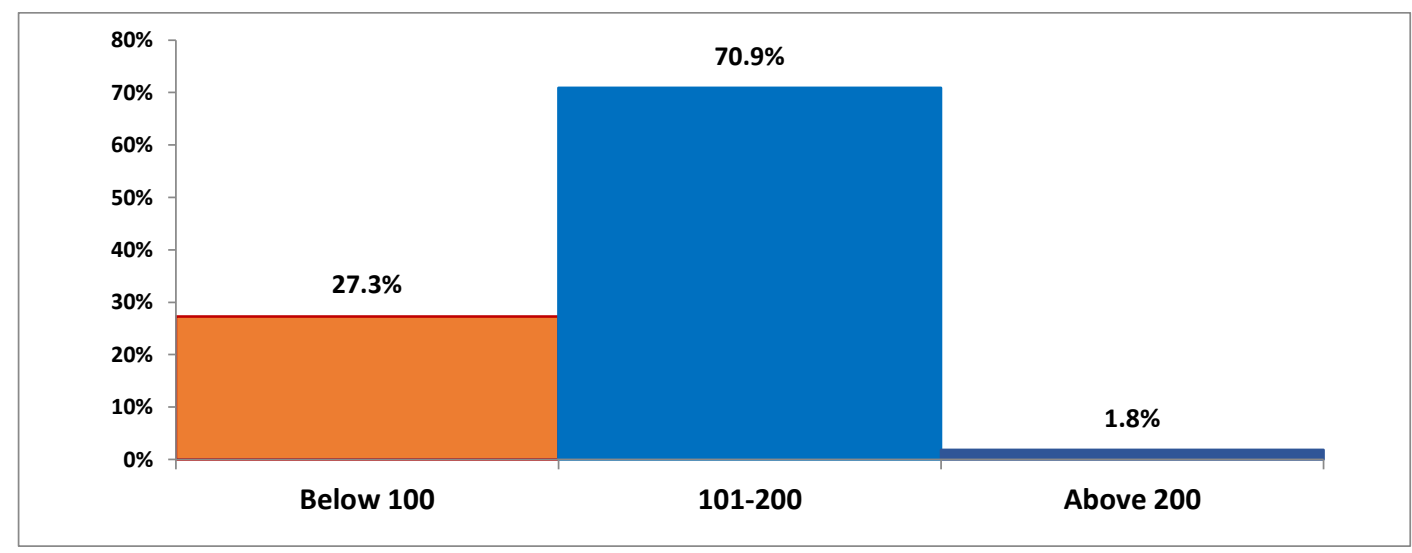

Figure 1: Total of user fee charges, $\%$

Out of 120 samples, only 55 respondents prefer private hospital where they have to yield out of user fee for their treatment and remaining respondents utilizes government hospital for the treatment. The results show that $70.9 \%$ of the private hospital respondents had spent between Rs101-200 for the treatment as a user charge, while 27.3\% pays below Rs100 as treatment fee. Treatment at the government hospital is either free or highly subsidized, yet a limited portion of the patients prefers to seek treatment from such facilities, only $1.8 \%$ of the private hospital respondents had spent more than Rs 200, Figure 1.

\section{- Diagnostic Charges}

A diagnostic test is a kind of medical test preferred to aid in the diagnosis or detection or diseases. It is a procedure performed to confirm or determine the presence of diseases in an individual suspected of having the diseases, usually following the report of symptoms, or based on the results of other medical tests or recovery from disease finally to confirm that a person is free from disease. Diagnostic charges often vary with the medical test taken from the person concerned and his/her disease status because there are many medical tests like blood test, urine test, X-Ray, measuring diabetics and blood pressure. Based on the illness the doctors administer some kind of tests on a person and report of the test which helps the doctor to diagnose the illness.

The results show that the diagnostic charges between Rs 201 and more than Rs 600 of the private hospital are more important than that the government hospital, Figure 2. On the other hand, more than $29 \%$ of the government hospital spends below than Rs 200 as diagnostic charges, although the private hospital spends only $14.5 \%$. No charges are focused in government hospital $(27.7 \%)$ than that in private hospital $(14.5 \%)$. Figure 2: Diagnostic charges paid by the respondents, $\%$ 


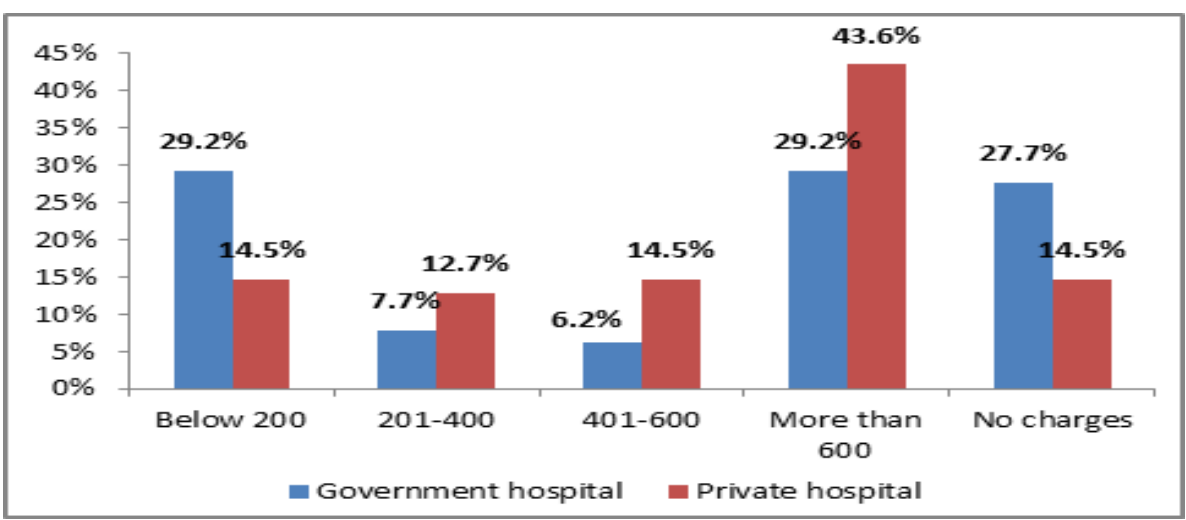

Figure 2: Diagnostic charges paid by the respondents, $\%$

Table 2 shows that $35.8 \%$ of the government hospital and private hospital spend more than Rs600 as diagnostic charges, followed by $22.5 \%$ paid below Rs 200, $10 \%$ paid between Rs 201 and Rs 600 , and $21.7 \%$ had no expenses for diagnostic services.

Table 2: Diagnostic charges

\begin{tabular}{|l|l|l|l|l|}
\hline Amount (Rs) & Government hospital & Private hospital & \multicolumn{2}{|c|}{ Total } \\
\cline { 3 - 5 } & & & Effective (Eff.) & \% \\
\hline Below 200 & 19 & 8 & $\mathbf{2 7}$ & $\mathbf{2 2 , 5 \%}$ \\
\hline $\mathbf{2 0 1 - 4 0 0}$ & 5 & 7 & $\mathbf{1 2}$ & $\mathbf{1 0 , 0 \%}$ \\
\hline $\mathbf{4 0 1 - 6 0 0}$ & 4 & 8 & $\mathbf{1 2}$ & $\mathbf{1 0 , 0 \%}$ \\
\hline More than 600 & 19 & 24 & $\mathbf{4 3}$ & $\mathbf{3 5 , 8 \%}$ \\
\hline No charges & 18 & 8 & $\mathbf{2 6}$ & $\mathbf{2 1 , 7 \%}$ \\
\hline Total & $\mathbf{6 5}$ & $\mathbf{5 5}$ & $\mathbf{1 2 0}$ & $\mathbf{1 0 0 , 0 \%}$ \\
\hline
\end{tabular}

Source: Field data

\section{- Medicine Charges}

Medicine is the art and science of healing the illness or injuries. It covers a range of health care practices evolved to maintain and regenerate health by the prevention and treatment of sickness. Indigenous medicine for hospitalized patients and preventive medicine refers to measures taken to prevent sickness or injury rather than healing them. The individual has to pay based on their illness. The price of medication is too high these days and the patients have to yield a heavy sum of money towards this. The medical charges paid by the respondents for the treatment in the study area are given in Table 3.

Table 3: Medicine charges

\begin{tabular}{|c|c|c|c|c|}
\hline \multirow{2}{*}{ Amount (Rs) } & \multicolumn{2}{|c|}{ Government hospital } & \multicolumn{2}{c|}{ Private hospital } \\
\cline { 2 - 5 } & Eff. & $\mathbf{\%}$ & Eff. & $\mathbf{\%}$ \\
\hline Below 500 & 21 & 32.3 & 9 & 16.4 \\
\hline $\mathbf{5 0 1 - 1 0 0 0}$ & 8 & 12.3 & 12 & 21.8 \\
\hline Above 1000 & 36 & 55.4 & 34 & 61.8 \\
\hline Total & $\mathbf{6 5}$ & $\mathbf{1 0 0 . 0}$ & $\mathbf{5 5}$ & $\mathbf{1 0 0 . 0}$ \\
\hline
\end{tabular}

Source: Field data 


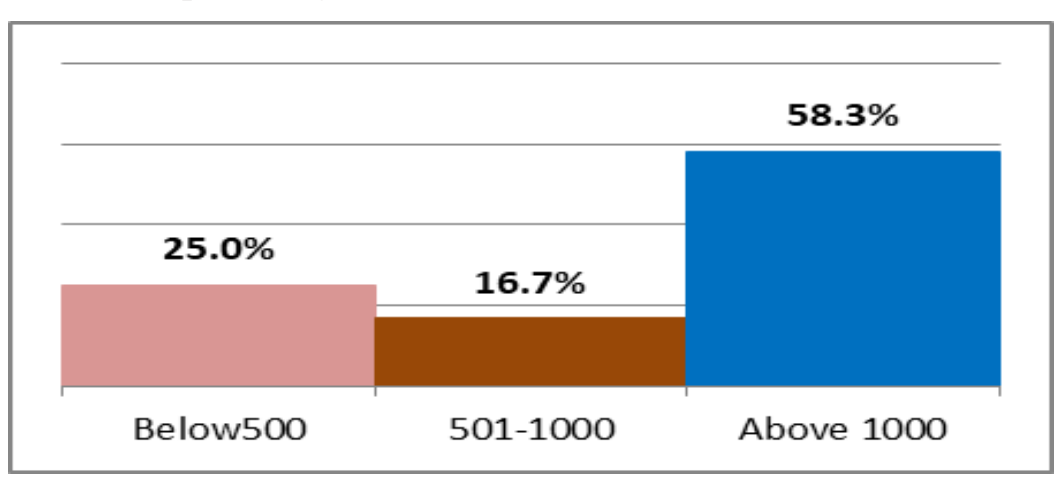

Figure 3: Total of Medicine charges, \%

Figure 3 shows that approximately $58.3 \%$ of both users pay above Rs1000, 25\% pay below Rs 500 , and remaining $16.7 \%$ pay between Rs 501-1000 for buying medication. The largest and most frequent cost incurred in treatment was for medicines. Those people going to government hospital may receive some free medicines, but generally they will be given prescriptions to buy medicines at the pharmacy nearby.

\section{- Surgical Charges}

Surgical treatment is one of the highest which pinches every one. The pain is not only experienced in physical state, but in financial terms also. When a surgery is done for a patient, it thwarts the whole set up of the family. Table 4 presents the surgical treatment charges among the surveyed population.

Table 4: Surgical charges

\begin{tabular}{|l|l|l|l|l|l|l|}
\hline \multirow{2}{*}{$\begin{array}{l}\text { Amount } \\
\text { (Rs) }\end{array}$} & \multicolumn{2}{|l|}{ Government hospital } & \multicolumn{2}{l|}{ Private hospital } & \multicolumn{2}{l|}{ Total } \\
\cline { 2 - 7 } Below 5000 & Eff. & \% & Eff. & \% & Eff. & $\%$ \\
\hline $\mathbf{5 0 0 1 - 1 0 0 0 0}$ & 1 & 13.8 & 0 & 0.0 & 9 & 7.5 \\
\hline $\mathbf{1 0 0 0 1 - 1 5 0 0 0}$ & 0 & 1.5 & 0 & 0.0 & 1 & 0.8 \\
\hline Above 15000 & 0 & 0.0 & 6 & 10.9 & 6 & 5.0 \\
\hline No charges & 55 & 84.6 & 23 & 41.8 & 78 & 65.0 \\
\hline Total & $\mathbf{6 5}$ & $\mathbf{1 0 0 . 0}$ & $\mathbf{5 5}$ & $\mathbf{1 0 0 . 0}$ & $\mathbf{1 2 0}$ & $\mathbf{1 0 0 . 0}$ \\
\hline
\end{tabular}

Source: Field data

The above table displays that $21.7 \%$ of the respondents who are seeking private health care services have spent Rs15000 and above as their surgical/operation charges, and 10.9\% spend between Rs 10001-15000. In the case of government hospital, 13.8\% spend below Rs5000 which represent $7.5 \%$ of total of the respondents. Also, $65 \%$ respondents opined that they had paid no charges in this regard where $84.6 \%$ are those of the government hospital.

\subsubsection{Indirect Cost of Healthcare}

The patients support also the charges indirectly linked to the health care which included, namely transportation charges, food and beverage charges and accommodation charges. The results of the study in accounting of indirect cost of respondents are presented as follows. 


\section{- Transportation Charges}

Transportation charges are indirect cost met by the sample respondents during the treatment. The payment for transportation (from residence to hospital) is shown Table 5.

Table 5: Transportation charges

\begin{tabular}{|c|c|c|c|c|}
\hline \multirow{2}{*}{ Amount (Rs) } & \multicolumn{2}{|c|}{ Government hospital } & \multicolumn{2}{c|}{ Private hospital } \\
\cline { 2 - 5 } & Eff. & \% & Eff. & \% \\
\hline Below 100 & 20 & 30.8 & 12 & 21.8 \\
\hline $\mathbf{1 0 1 - 2 0 0}$ & 11 & 16.9 & 17 & 30.9 \\
\hline 201-300 & 17 & 26.2 & 2 & 3.6 \\
\hline Above 300 & 17 & 26.2 & 24 & 43.6 \\
\hline Total & $\mathbf{6 5}$ & $\mathbf{1 0 0 . 0}$ & $\mathbf{5 5}$ & $\mathbf{1 0 0 . 0}$ \\
\hline
\end{tabular}

Source: Field data

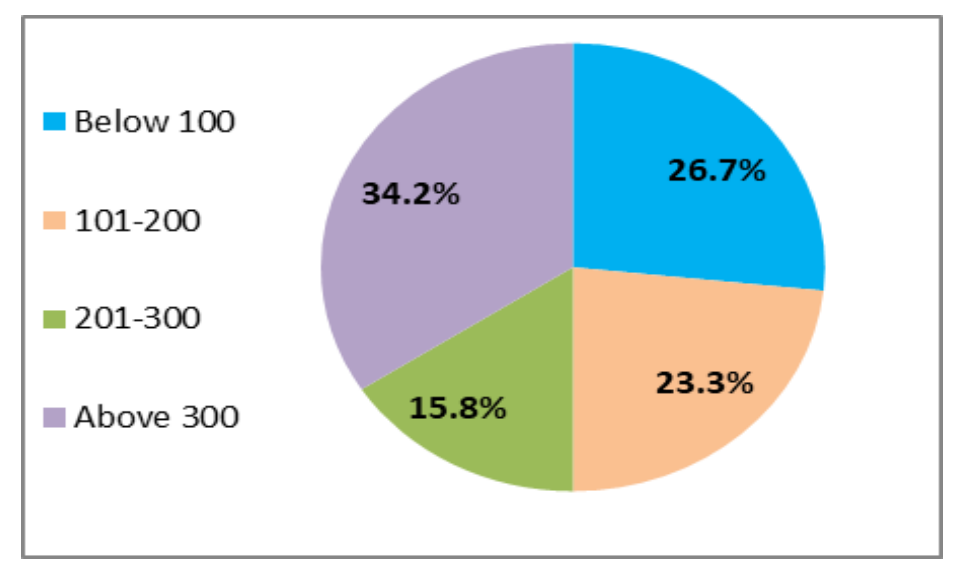

Figure 4: Total of Transportation charges, \%

On the whole, the majority of the respondents (34.2\%) spend above Rs 300 as transportation charges, $26.7 \%$ spend below Rs100, and 23.3\% spend between Rs101-200; whereas 15.8\% of the respondents spend between Rs 201-300, Figure 4.

\section{- Food and Beverages Charges}

Food and beverages charges are also other indirect cost met by the sample respondents during the treatment. This will occur when the person is hospitalized/ even when they come to the consultation. The expenses incurred for food and beverages are shown Table 6.

Table 6: Food and beverages charges

\begin{tabular}{|c|c|c|c|c|}
\hline \multirow{2}{*}{ Amount (Rs) } & \multicolumn{2}{|c|}{ Government hospital } & \multicolumn{2}{c|}{ Private hospital } \\
\cline { 2 - 5 } & Eff. & $\mathbf{\%}$ & Eff. & $\mathbf{\%}$ \\
\hline Below 500 & 31 & 47.7 & 15 & 27.3 \\
\hline 501-1000 & 23 & 35.4 & 20 & 36.4 \\
\hline Above 1000 & 1 & 1.5 & 15 & 27.3 \\
\hline No charges & 10 & 15.4 & 5 & 9.1 \\
\hline Total & $\mathbf{6 5}$ & $\mathbf{1 0 0}$ & $\mathbf{5 5}$ & $\mathbf{1 0 0}$ \\
\hline
\end{tabular}

Source: Field data 


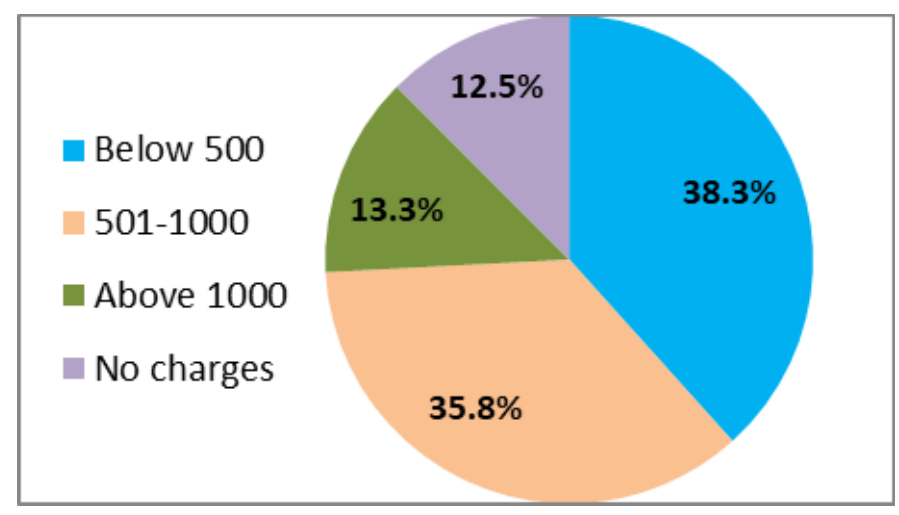

Figure 5: Total of Food and beverages charges, \%

On the whole, nearly $38 \%$ of government and private hospital users spend below 500 for food and beverages, while $35.8 \%$ spend between Rs501-1000 and $13.33 \%$ spends above Rs 1000 for food and beverages per visit, Figure 5.

\section{- Accommodation Charges}

Accommodation charges are also an important indirect cost met by the respondents, because when the respondents are hospitalized there is a need for one person to accompany them, for which they have to pay charges day or need to pay room rent at the hospital. Table 7 shows accommodation charges incurred by the respondents.

Table 7: Accommodation charges

\begin{tabular}{|c|c|c|c|c|}
\hline \multirow{2}{*}{ Amount (Rs) } & \multicolumn{2}{|c|}{ Government hospital } & \multicolumn{2}{c|}{ Private hospital } \\
\cline { 2 - 5 } & Eff. & $\mathbf{\%}$ & Eff. & \% \\
\hline Below 500 & 23 & 35.4 & 1 & 1.8 \\
\hline 501-1000 & 0 & 0.0 & 10 & 18.2 \\
\hline Above 1000 & 0 & 0.0 & 21 & 38.2 \\
\hline No charges & 42 & 64.6 & 23 & 41.8 \\
\hline Total & $\mathbf{6 5}$ & $\mathbf{1 0 0}$ & $\mathbf{5 5}$ & $\mathbf{1 0 0}$ \\
\hline
\end{tabular}

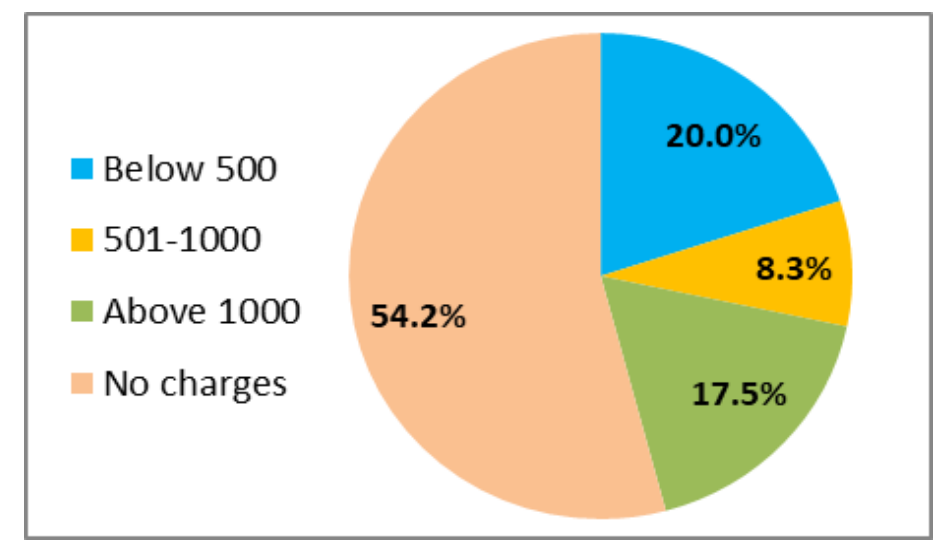

Figure 6: Total of Accommodation charges, \%

The accommodation charges in government hospital are less than that of private hospital. $64.6 \%$ respondents in government hospital have no accommodation charges, and $35.4 \%$ had 
accommodation charges below Rs 500. However in private hospital respondents, $38.2 \%$ spend above Rs 1000 as accommodation charges and 18.2\% spend between Rs 501 and Rs 1000 that is $25.8 \%$ of the total respondents. The variations in accommodation charge may be due to the variations in facilities and quality of health care services both inside and outside the premises of the hospitals.

\subsubsection{Expenditure Mode: Direct and Indirect Costs}

The average expenditure spends on direct costs and indirect costs for the treatment are presented in the Table 8. Direct cost included four types of charges: user fee, diagnostic, medicine and surgical. Indirect cost included three types of charges: transportation, food and beverages, and accommodation.

Table 8: Average expenditure on direct and indirect cost, in Rs

\begin{tabular}{|l|l|l|}
\hline Charges & Government hospital & Private hospital \\
\hline Direct costs & 0 & 140 \\
\hline User fee & 121.65 & 172.42 \\
\hline Diagnostic & 487.97 & 521.83 \\
\hline Medicine & 261.54 & 2163.64 \\
\hline Surgical & $\mathbf{8 7 1 . 1 6}$ & $\mathbf{2 9 9 7 . 8 9}$ \\
\hline Total (1) & \multicolumn{2}{|l|}{} \\
\hline Indirect costs & 101.59 & 124.97 \\
\hline Transportation & 127.21 & 309.30 \\
\hline Food and beverages & 35.38 & 649.36 \\
\hline Accommodation & 264.18 & $\mathbf{3 6 4 7 . 2 5}$ \\
\hline Total (2) & $\mathbf{1 1 3 5 . 3 4}$ & \\
\hline Total(3)=(1)+(2) &
\end{tabular}

Source: Field data (per patient)

The total cost of health care consists of direct and indirect cost. Among government hospital users the total health care cost was Rs1135.34 which direct cost was Rs 871.16 and indirect cost was Rs 264.18. Similarly for users of private hospital it was Rs 2997.89 and Rs 649.36 respectively. The cost incurred by the private hospital user was higher. It is concluded that treatment in private hospital was more expensive as compared to that of government hospitals.

\subsection{Total Health Expenditure}

The utilization of health services and the preference of people to use certain facilities are not only determined by the easy accessibility and good quality of services, but also by the economic level of the respondents and costs of treatment which appear to be an equally important factor. Total expenditure on health includes doctor fee, medicine charge, diagnostic care, surgical care, transportation, and food and accommodation charges. The expenditure incurred by the sample respondents is calculated and presented the below Table 9. 
Table 9: Total health expenditure

\begin{tabular}{|l|l|l|l|l|l|l|}
\hline \multirow{2}{*}{ Amount (Rs) } & \multicolumn{2}{|l|}{ Government hospital } & \multicolumn{2}{l|}{ Private hospital } & \multicolumn{2}{l|}{ Total } \\
\cline { 2 - 7 } & Eff. & $\%$ & Eff. & $\%$ & Eff. & $\%$ \\
\hline Below 4000 & 40 & 61.5 & 11 & 20.0 & 51 & 42.5 \\
\hline $\mathbf{4 0 0 0 - 7 0 0 0}$ & 17 & 26.2 & 22 & 40.0 & 39 & 32.5 \\
\hline $\mathbf{7 0 0 0 - 1 0 0 0 0}$ & 5 & 7.7 & 2 & 3.6 & 7 & 5.8 \\
\hline Above 10000 & 3 & 4.6 & 20 & 36.4 & 23 & 19.2 \\
\hline Total & $\mathbf{6 5}$ & $\mathbf{1 0 0}$ & $\mathbf{5 5}$ & $\mathbf{1 0 0}$ & $\mathbf{1 2 0}$ & $\mathbf{1 0 0}$ \\
\hline
\end{tabular}

Source: Field data

This table reveals that in government hospital 61.5\% respondents had expenditure below Rs 4000, about $26 \%$ respondents had expenditure between Rs 4000 and Rs 7000 and only $12.3 \%$ had expenditure more than Rs 7000. In the case of private hospital, $40 \%$ respondents had expenditure between Rs 4000-7000, 36.4\% respondents had expenditure above Rs 10000, and 20\% respondents had expenditure below Rs 4000; while only 3.6\% respondents had expenditure between Rs 7000 and Rs10000.

According to these results, two main remarks can be discovered:(1) the expenditure on health in private hospital is high compared to a government hospital which majority of the respondents had expenditure more than Rs 10000 in the private hospital, and (2) more than $42 \%$ respondents had expenditure below Rs 4000 in both private and government hospital.

\subsection{Characteristics Socio-economics}

The demand of health depends on various factors such as income, age, gender, marital status, level of education, spatial distribution and occupation. For that, the results of the present study are presented as follows.

\section{- Monthly Income}

The pattern of expenditure on health by the various income groups is analysed.Table 10 reveals that in the event of government hospital out of 65 sample respondents, $66.2 \%$ of the people spend below Rs 4000 and 21.5\% spend between Rs 4001 and Rs 7000; although 7.7\% of the people spend between Rs 7001 and Rs10000, and 4.6\% spend above Rs10000. Other remarks are (i) $13.8 \%$ of the people had income below Rs 4000 and spend amount less than Rs 4000, (ii) No one had income below Rs 4000 and can spend Rs 7001-10000 and above Rs10000, (iii) 16.9\% respondents had income Rs 4001-7000 and spend below Rs 4000, (iv) 9.2\% respondents had income Rs 4001-7000 and spend Rs 4001-7000, and (v) 4.6\% spend 7001-10000. In the case of no income, $12.3 \%$ people were spending more below Rs 4000 and $6.2 \%$ were spending Rs 4001 7000 .

Table 10: Health expenditure and monthly income

\begin{tabular}{|l|l|l|l|l|l|l|l|l|l|l|}
\hline & \multicolumn{8}{|c|}{ Health expenditure } \\
\hline \multirow{3}{*}{ Monthly income } & Below 4000 & $\mathbf{4 0 0 1 - 7 0 0 0}$ & $\mathbf{7 0 0 1 - 1 0 0 0 0}$ & Above 10000 & \multicolumn{2}{|c|}{ Total } \\
\cline { 2 - 10 } & Eff. & $\%$ & Eff. & $\mathbf{\%}$ & Eff. & $\mathbf{\%}$ & Eff. & \% & Eff. & \% \\
\cline { 2 - 10 } & \multicolumn{8}{|c|}{ Government hospital } \\
\hline Below 4000 & 9 & 13.8 & 1 & 1.5 & 0 & 0.0 & 0 & 0.0 & 10 & 15.4 \\
\hline
\end{tabular}




\begin{tabular}{|l|l|l|l|l|l|l|l|l|l|l|}
\hline $\mathbf{4 0 0 1 - 7 0 0 0}$ & 11 & 16.9 & 6 & 9.2 & 3 & 4.6 & 1 & 1.5 & 21 & 32.3 \\
\hline $\mathbf{7 0 0 1 - 1 0 0 0 0}$ & 9 & 13.8 & 0 & 0.0 & 1 & 1.5 & 0 & 0.0 & 10 & 15.4 \\
\hline Above 10000 & 6 & 9.2 & 3 & 4.6 & 0 & 0.0 & 1 & 1.5 & 10 & 15.4 \\
\hline No income & 8 & 12.3 & 4 & 6.2 & 1 & 1.5 & 1 & 1.5 & 14 & 21.5 \\
\hline Total (1) & $\mathbf{4 3}$ & $\mathbf{6 6 . 2}$ & $\mathbf{1 4}$ & $\mathbf{2 1 . 5}$ & $\mathbf{5}$ & $\mathbf{7 . 7}$ & $\mathbf{3}$ & $\mathbf{4 . 6}$ & $\mathbf{6 5}$ & $\mathbf{1 0 0}$ \\
\hline \multicolumn{8}{|l|}{ Private hospital } \\
\hline Below 4000 & 2 & 3.6 & 5 & 9.1 & 0 & 0.0 & 3 & 5.5 & 10 & 18.2 \\
\hline $\mathbf{4 0 0 1 - 7 0 0 0}$ & 2 & 3.6 & 1 & 1.8 & 1 & 1.8 & 5 & 9.1 & 9 & 16.4 \\
\hline $\mathbf{7 0 0 1 - 1 0 0 0 0}$ & 7 & 12.7 & 1 & 1.8 & 0 & 0.0 & 6 & 10.9 & 14 & 25.5 \\
\hline Above 10000 & 3 & 5.5 & 3 & 5.5 & 0 & 0.0 & 5 & 9.1 & 11 & 20.0 \\
\hline No income & 9 & 16.4 & 1 & 1.8 & 0 & 0.0 & 1 & 1.8 & 11 & 20.0 \\
\hline Total (2) & $\mathbf{2 3}$ & $\mathbf{4 1 . 8}$ & $\mathbf{1 1}$ & $\mathbf{2 0 . 0}$ & $\mathbf{1}$ & $\mathbf{1 . 8}$ & $\mathbf{2 0}$ & $\mathbf{3 6 . 4}$ & $\mathbf{5 5}$ & $\mathbf{1 0 0}$ \\
\hline
\end{tabular}

Source: Field data

In the case of private hospital out of 55 sample respondents, the above table reveals the following remarks: (i)3.6\% respondents had income below Rs4000 and 5.5\% had income above Rs 10000 and spend also more than Rs 10000, (ii) 1.8\% of the respondents had an income Rs 4001-7000 and spends Rs 4001-7000, (iii) 12.7\% had income below Rs 4001-7000 and spend also below Rs 4000, and (iv) 16.4\% had income above Rs 10000 and spend below Rs 4000. So, there is a positive relationship between income and health expenditure: when income increases the expenditure also increases, Figure 7.

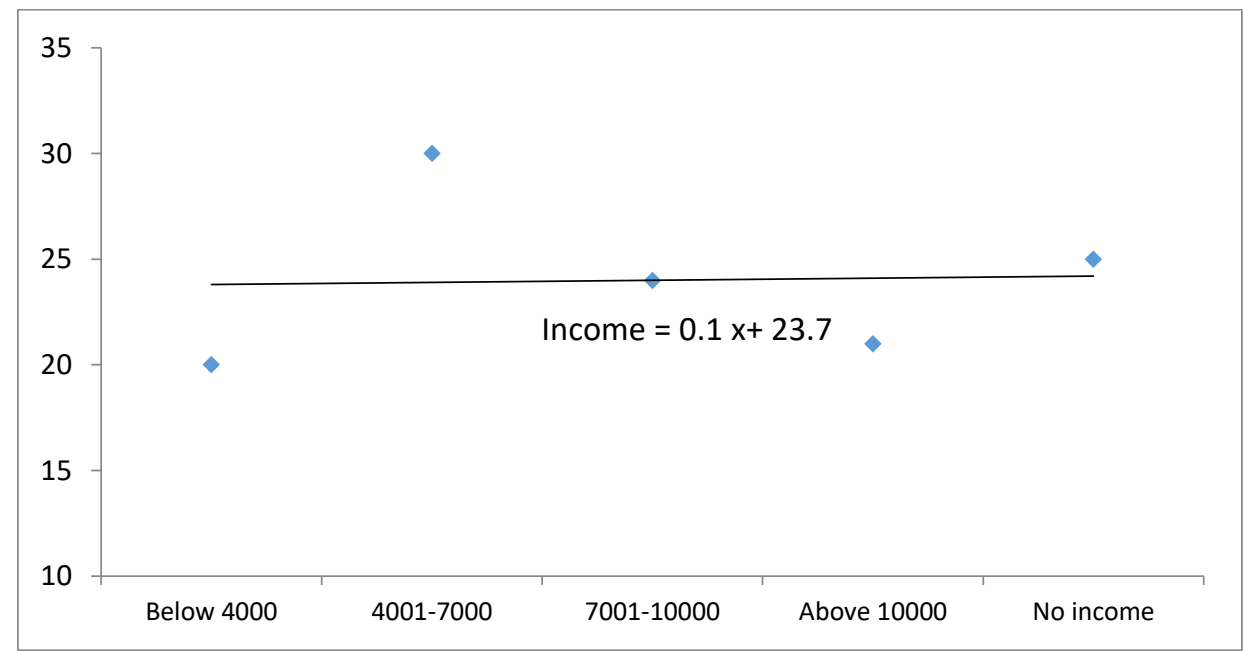

Figure 7: Relationship between income and health expenditure

\section{- Age Group}

In the case of 65 sample respondents in the government hospital, according to Table 11, (i) $40 \%$ of the respondents belong to the age group below 50 spend amount less than Rs4000, (ii) No one can spend Rs 10000 in the age group above 50, (iii) 7.7\% respondents spend between Rs 40017000 they belongs to the age group 31-50, (iv) 3.2\% respondents spend between Rs 7001-1000 and they belonged to the age group 31-50, and (v) In the age belongs below 30 they spend no amount between Rs 7001-10000. 
Table 11: Health expenditure and age

\begin{tabular}{|c|c|c|c|c|c|c|c|c|c|c|}
\hline \multirow[t]{4}{*}{ Monthly income } & \multicolumn{10}{|c|}{ Health expenditure } \\
\hline & \multicolumn{2}{|c|}{ Below 4000} & \multicolumn{2}{|c|}{ 4001-7000 } & \multicolumn{2}{|c|}{$7001-10000$} & \multicolumn{2}{|c|}{ Above 10000} & \multicolumn{2}{|c|}{ Total } \\
\hline & Eff. & $\%$ & Eff. & $\%$ & Eff. & $\%$ & Eff. & $\%$ & Eff. & $\%$ \\
\hline & \multicolumn{10}{|c|}{ Government hospital } \\
\hline Below 30 & 13 & 20.0 & 5 & 7.7 & 0 & 0.0 & 1 & 1.5 & 19 & 29.2 \\
\hline $31-50$ & 13 & 20.0 & 5 & 7.7 & 2 & 3.1 & 2 & 3.1 & 22 & 33.8 \\
\hline Above 50 & 17 & 26.2 & 4 & 6.2 & 3 & 4.6 & 0 & 0.0 & 24 & 36.9 \\
\hline \multirow[t]{2}{*}{ Total (1) } & 43 & 66.2 & 14 & 21.5 & 5 & 7.7 & 3 & 4.6 & 65 & 100 \\
\hline & \multicolumn{10}{|c|}{ Private hospital } \\
\hline Below 30 & 10 & 18.2 & 3 & 5.5 & 0 & 0.0 & 4 & 7.3 & 17 & 30.9 \\
\hline $31-50$ & 7 & 12.7 & 2 & 3.6 & 0 & 0.0 & 13 & 23.6 & 22 & 40.0 \\
\hline Above 50 & 6 & 10.9 & 6 & 10.9 & 1 & 1.8 & 3 & 5.5 & 16 & 29.1 \\
\hline Total (2) & 23 & 41.8 & 11 & 20.0 & 1 & 1.8 & 20 & 36.4 & 55 & 100.0 \\
\hline
\end{tabular}

Source: Field data

Table 11 reveals also that in the case of private hospital out of 55 sample respondents, (i) $18.2 \%$ respondents belong to the age group below 30 and they spend under Rs 4000, (ii) $10.9 \%$ belongs to the age group 31-50 and spend between Rs 4001-7000, (iii) $1.8 \%$ of the respondents belong to the age above 50 and spends between Rs 7001-1000, and (iv) $23.6 \%$ belongs to the age between 31-50 and spend also more than Rs 10000.

\section{- Gender}

In the case of 65 sample respondents in the government hospital, $(i) 44.6 \%$ were male respondents and they spend under Rs 4000, (ii) $13.8 \%$ were females and they spend between Rs 4000-7000, (iii) $6.2 \%$ females spend between Rs 7001-10000, and (iv) 1.5\% males spend more than Rs 10000 . In the case of private hospital, Table 12 reveals also that (i) $23.6 \%$ was males and they spend below Rs 4000, (ii) 10.9\% females spend between Rs 4001-7000, (iii) No male respondents spend between the amounts Rs 7001-10000, and (iv) 21.3\% female respondents spend more than Rs 10000 .

Table 12: Health expenditure and gender

\begin{tabular}{|c|c|c|c|c|c|c|c|c|c|c|}
\hline \multirow[t]{4}{*}{ Gender } & \multicolumn{10}{|c|}{ Health expenditure } \\
\hline & \multicolumn{2}{|c|}{ Below 4000} & \multicolumn{2}{|c|}{$4001-7000$} & \multicolumn{2}{|c|}{$7001-10000$} & \multicolumn{2}{|c|}{ Above 10000 } & \multicolumn{2}{|c|}{ Total } \\
\hline & Eff. & $\%$ & Eff. & $\%$ & Eff. & $\%$ & Eff. & $\%$ & Eff. & $\%$ \\
\hline & \multicolumn{10}{|c|}{ Government hospital } \\
\hline Male & 29 & 44.6 & 5 & 7.7 & 1 & 1.5 & 1 & 1.5 & 36 & 55.4 \\
\hline Female & 14 & 21.5 & 9 & 13.8 & 4 & 6.2 & 2 & 3.1 & 29 & 44.6 \\
\hline Total (1) & 43 & 66.1 & 14 & 21.5 & 5 & 7.7 & 3 & 4.6 & 65 & 100.0 \\
\hline & \multicolumn{10}{|c|}{ Private hospital } \\
\hline Male & 13 & 23.6 & 5 & 9.1 & 0 & 0.0 & 8 & 14.5 & 26 & 47.3 \\
\hline Female & 10 & 18.2 & 6 & 10.9 & 1 & 1.8 & 12 & 21.8 & 29 & 52.7 \\
\hline Total (2) & 23 & 41.8 & 11 & 20.0 & 1 & 1.8 & 20 & 36.4 & 55 & 100.0 \\
\hline
\end{tabular}

Source: Field data 
The results of the relationships between expenditure health and gender show that the female prefers the private hospital $(52.7 \%)$, Figure 8.

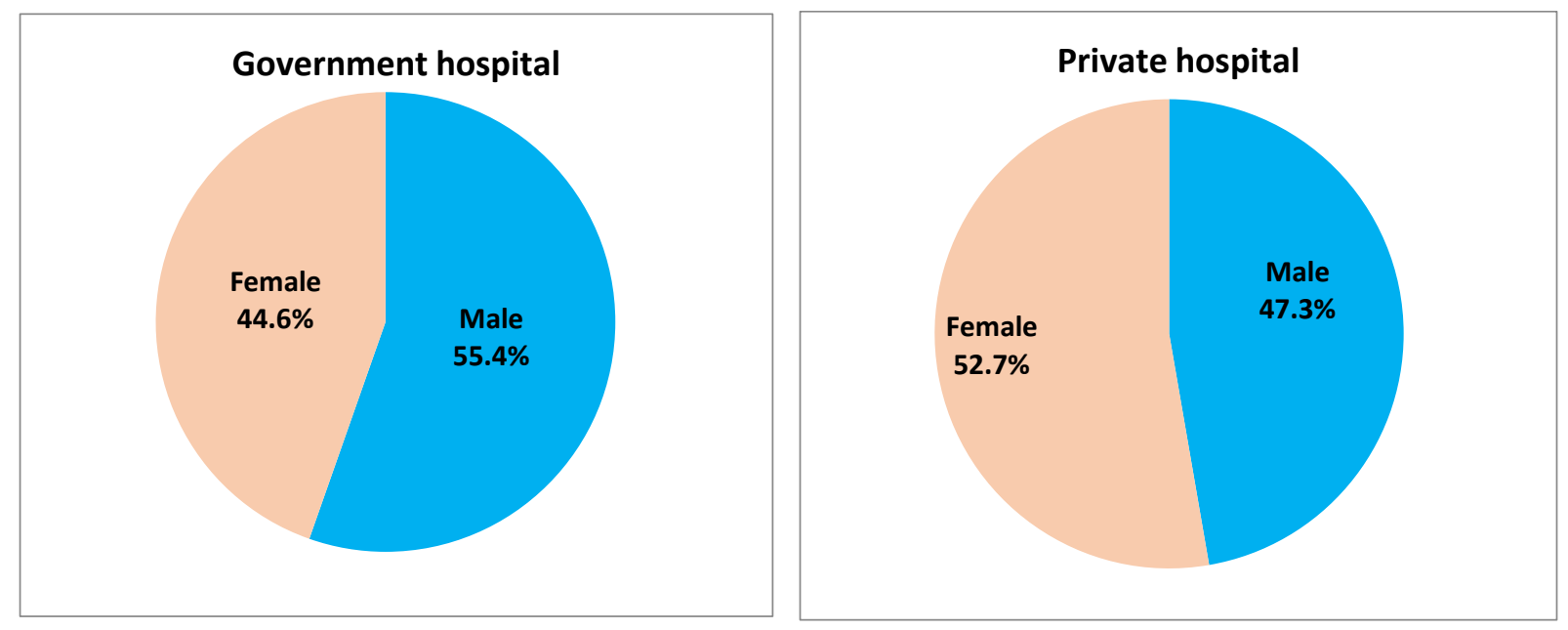

Figure 8: Expenditure health and gender

\section{- Marital Status}

In the case of a government hospital out of 65 sample respondents, Table 13 shows that (i) $49.2 \%$ are married and they spend under Rs 4000, (ii) 9.2\% are single or unmarried and they spend between Rs 4001-7000, (iii) 6.2\% were married respondents and they spend between Rs 700110000, and (iv) $1.5 \%$ single or unmarried respondents spend more than Rs 10000.

Table 13: Health expenditure and marital status

\begin{tabular}{|l|l|l|l|l|l|l|l|l|l|l|l|l|}
\hline & \multicolumn{10}{|c|}{ Health expenditure } \\
\hline \multirow{3}{*}{ Marital status } & Below 4000 & $\mathbf{4 0 0 1 - 7 0 0 0}$ & $\mathbf{7 0 0 1 - 1 0 0 0 0}$ & Above 10000 & \multicolumn{2}{|c|}{ Total } \\
\cline { 2 - 12 } & Eff. & $\mathbf{\%}$ & Eff. & $\mathbf{\%}$ & Eff. & $\mathbf{\%}$ & Eff. & $\mathbf{\%}$ & Eff. & \% \\
\cline { 2 - 12 } & \multicolumn{8}{|c|}{ Government hospital } \\
\hline Single/ unmarried & 11 & 16.9 & 6 & 9.2 & 1 & 1.5 & 1 & 1.5 & 19 & 29.2 \\
\hline Married & 32 & 49.2 & 8 & 12.3 & 4 & 6.2 & 2 & 3.1 & 46 & 70.8 \\
\hline Total (1) & $\mathbf{4 3}$ & $\mathbf{6 6 . 2}$ & $\mathbf{1 4}$ & $\mathbf{2 1 . 5}$ & $\mathbf{5}$ & $\mathbf{7 . 7}$ & $\mathbf{3}$ & $\mathbf{4 . 6}$ & $\mathbf{6 5}$ & $\mathbf{1 0 0 . 0}$ \\
\hline & \multicolumn{8}{|c|}{ Private hospital } & & \\
\hline Single/ unmarried & 6 & 10.9 & 2 & 3.6 & 0 & 0.0 & 3 & 5.5 & 11 & 20.0 \\
\hline Married & 17 & 30.9 & 9 & 16.4 & 1 & 1.8 & 17 & 30.9 & 44 & 80.0 \\
\hline Total (2) & $\mathbf{2 3}$ & $\mathbf{4 1 . 8}$ & $\mathbf{1 1}$ & $\mathbf{2 0 . 0}$ & $\mathbf{1}$ & $\mathbf{1 . 8}$ & $\mathbf{2 0}$ & $\mathbf{3 6 . 4}$ & $\mathbf{5 5}$ & $\mathbf{1 0 0 . 0}$ \\
\hline
\end{tabular}

\section{Source: Field data}

In the case of private hospital out of 55 sample respondents, the sametable shows that (i) $30.9 \%$ are married and they spend under Rs 4000, (ii) 3.6\% were single or unmarried respondents and they spend between Rs 4001-7000, (iii) 1.8\%are married respondents and spend between Rs 700110000, and (iv)30.9\% are married respondents and spend more than Rs 10000. We remark that majority of respondents in both cases are married, i.e. $70.8 \%$ for government hospital and $80.0 \%$ for private hospital. 


\section{- Education Level}

In the case of 65 sample respondents in the government hospital, Table 14 reveals that (i)13.8\% respondents have attained primary level education and they spend below Rs 4000, (ii)6.2\% attained high school education and they spend between Rs 4001-7000, (iii)only $1.5 \%$ attained higher secondary education and they spend between Rs 7001-10000, and (iv) 15.5\% spend below Rs 4000 and they have got higher education.

Table 14: Health expenditure and education

\begin{tabular}{|c|c|c|c|c|c|c|c|c|c|c|}
\hline \multirow{4}{*}{ Education } & \multicolumn{10}{|c|}{ Health expenditure } \\
\hline & \multicolumn{2}{|c|}{ Below 4000} & \multicolumn{2}{|c|}{ 4001-7000 } & \multicolumn{2}{|c|}{$7001-10000$} & \multicolumn{2}{|c|}{ Above 10000} & \multicolumn{2}{|c|}{ Total } \\
\hline & Eff. & $\%$ & Eff. & $\%$ & Eff. & $\%$ & Eff. & $\%$ & Eff. & $\%$ \\
\hline & \multicolumn{10}{|c|}{ Government hospital } \\
\hline Illiterate & 6 & 9.2 & 0 & 0.0 & 1 & 1.5 & 0 & 0.0 & 7 & 10.8 \\
\hline Primary & 9 & 13.8 & 3 & 4.6 & 2 & 3.1 & 1 & 1.5 & 15 & 23.1 \\
\hline High school & 10 & 15.4 & 6 & 9.2 & 1 & 1.5 & 2 & 3.1 & 19 & 29.2 \\
\hline Higher secondary & 5 & 7.7 & 1 & 1.5 & 1 & 1.5 & 0 & 0.0 & 7 & 10.8 \\
\hline Higher education & 10 & 15.4 & 4 & 6.2 & 0 & 0.0 & 0 & 0.0 & 14 & 21.5 \\
\hline Others & 3 & 4.6 & 0 & 0.0 & 0 & 0.0 & 0 & 0.0 & 3 & 4.6 \\
\hline \multirow[t]{2}{*}{ Total (1) } & 43 & 66.2 & 14 & 21.5 & 5 & 7.7 & 3 & 4.6 & 65 & 100.0 \\
\hline & \multicolumn{10}{|c|}{ Private hospital } \\
\hline Illiterate & 1 & 1.8 & 0 & 0.0 & 0 & 0.0 & 2 & 3.6 & 3 & 5.5 \\
\hline Primary & 3 & 5.5 & 5 & 9.1 & 0 & 0.0 & 3 & 5.5 & 11 & 20.0 \\
\hline High school & 5 & 9.1 & 0 & 0.0 & 1 & 1.8 & 3 & 5.5 & 9 & 16.4 \\
\hline Higher secondary & 7 & 12.7 & 3 & 5.5 & 0 & 0.0 & 4 & 7.3 & 14 & 25.5 \\
\hline Higher education & 7 & 12.7 & 2 & 3.6 & 0 & 0.0 & 8 & 14.5 & 17 & 30.9 \\
\hline Others & 0 & 0.0 & 1 & 1.8 & 0 & 0.0 & 0 & 0.0 & 1 & 1.8 \\
\hline Total (2) & 23 & 41.8 & 11 & 20.0 & 1 & 1.8 & 20 & 36.4 & 55 & 100.0 \\
\hline
\end{tabular}

Source: Field data

In the case of private hospital out of 55 sample respondents, the above table indicates also that (i) $3.6 \%$ respondents were illiterate and they spend more than Rs 10000, (ii) $9.1 \%$ attained primary education and they spend between Rs 4001-7000, (iii) 12.7\% spend under Rs 4000 they have got a high school education, and (iv) 14.5\% spend more than Rs 10000 and they attained higher education.

On the whole, private hospital has got $25.5 \%$ respondents were higher secondary and $30.9 \%$ respondents were higher education than that in the case of government hospital, Figure 9. 


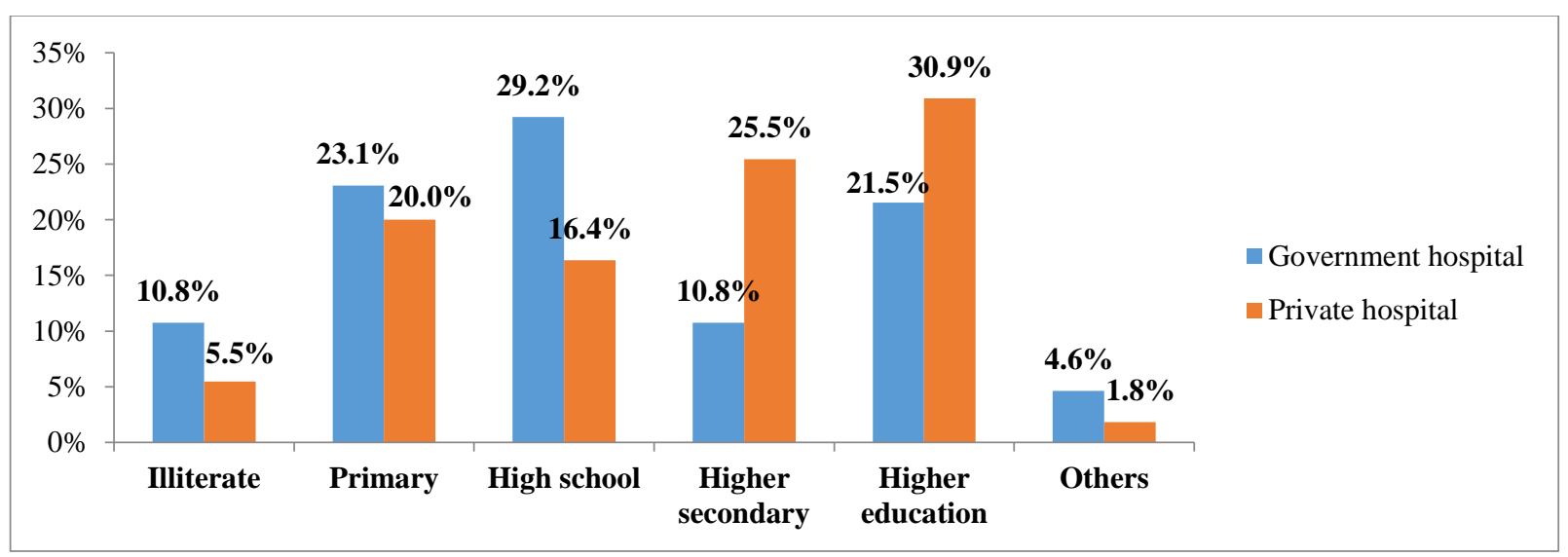

Figure 9: Total health expenditure and education

\section{- Spatial distribution}

In government hospital out of 65 sample respondents, Table 15 reveals that (i) $43.1 \%$ residing in urban area and spend under Rs 4000, (ii) $9.2 \%$ were residing in the rural area and spend between Rs 4001-7000, (iii) 4.6\% residing in urban area and spend between Rs 7001 and Rs10000, and (iv) $3.1 \%$ residing in the rural area and spend more than Rs 10000 . Moreover, in the case of private hospital out of 55 sample respondents, (i) $29.1 \%$ residing in urban area and spend under Rs 4000, (ii) $12.7 \%$ residing in rural and spend between Rs 4001 and Rs 7000, (iii) $1.8 \%$ residing in the rural area and spend Rs 7001-10000, and (iv) 18.2\% respondents in the rural and urban areas spend more than Rs 10000.

Table 15: Expenditure and spatial distribution

\begin{tabular}{|c|c|c|c|c|c|c|c|c|c|c|}
\hline \multirow{4}{*}{ Spatial distribution } & \multicolumn{10}{|c|}{ Health expenditure } \\
\hline & \multicolumn{2}{|c|}{ Below 4000} & \multicolumn{2}{|c|}{ 4001-7000 } & \multicolumn{2}{|c|}{$7001-10000$} & \multicolumn{2}{|c|}{ Above 10000} & \multicolumn{2}{|c|}{ Total } \\
\hline & Eff. & $\%$ & Eff. & $\%$ & Eff. & $\%$ & Eff. & $\%$ & Eff. & $\%$ \\
\hline & \multicolumn{10}{|c|}{ Government hospital } \\
\hline Urban & 28 & 43.1 & 8 & 12.3 & 3 & 4.6 & 1 & 1.5 & 40 & 61.5 \\
\hline Rural & 15 & 23.1 & 6 & 9.2 & 2 & 3.1 & 2 & 3.1 & 25 & 38.5 \\
\hline \multirow[t]{2}{*}{ Total (1) } & 43 & 66.2 & 14 & 21.5 & 5 & 7.7 & 3 & 4.6 & 65 & 100.0 \\
\hline & \multicolumn{10}{|c|}{ Private hospital } \\
\hline Urban & 16 & 29.1 & 4 & 7.3 & 0 & 0.0 & 10 & 18.2 & 30 & 54.5 \\
\hline Rural & 7 & 12.7 & 7 & 12.7 & 1 & 1.8 & 10 & 18.2 & 25 & 45.5 \\
\hline Total (2) & 23 & 41.8 & 11 & 20.0 & 1 & 1.8 & 20 & 36.4 & 55 & 100.0 \\
\hline
\end{tabular}

Source: Field data

On the whole, respondents residing in urban area are more in number than that residing in rural area in both government and private hospitals, Figure 10. The finding shows the penetration of private hospitals in the urban areas, whereas, both services are scarce in rural areas. 

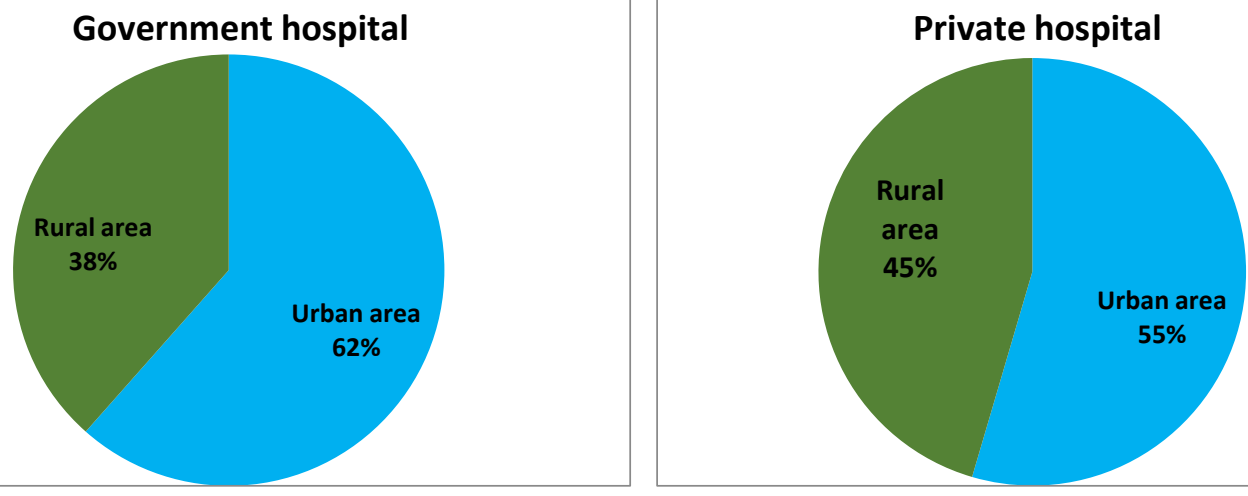

Figure 10: Total expenditure and spatial distribution

\section{- Occupation}

Table 17 reveals that among the respondents seeking health care in government hospitals, $(i) 7.7 \%$ engaged in government or public sector jobs and they spend below Rs 4000, (ii) $1.5 \%$ respondents take the private sector job and they spend betweenRs 4001-7000, (iii) approximately 3\% engaged in business and they spend more than Rs 10000, (iv) 10.8\% agricultural labour spend below Rs 4000 , (v) 15.4\% undertakes occupation as coolie and they spend under Rs 4000, (vi) $6.2 \%$ respondents are unemployed and they spend between Rs 7001 and Rs 10000.

Table 16: Expenditure and occupation

\begin{tabular}{|c|c|c|c|c|c|c|c|c|c|c|}
\hline \multirow{4}{*}{ Occupation } & \multicolumn{10}{|c|}{ Health expenditure } \\
\hline & \multicolumn{2}{|c|}{ Below 4000} & \multicolumn{2}{|c|}{ 4001-7000 } & \multicolumn{2}{|c|}{$7001-10000$} & \multicolumn{2}{|c|}{\begin{tabular}{|l|} 
Above 10000 \\
\end{tabular}} & \multicolumn{2}{|c|}{ Total } \\
\hline & Eff. & $\%$ & Eff. & $\%$ & Eff. & $\%$ & Eff. & $\%$ & Eff. & $\%$ \\
\hline & \multicolumn{10}{|c|}{ Government hospital } \\
\hline Government/ public & 5 & 7.7 & 1 & 1.5 & 0 & 0.0 & 0 & 0.0 & 6 & 9.2 \\
\hline Private sector & 8 & 12.3 & 1 & 1.5 & 1 & 1.5 & 0 & 0.0 & 10 & 15.4 \\
\hline Business & 5 & 7.7 & 1 & 1.5 & 0 & 0.0 & 2 & 3.1 & 8 & 12.3 \\
\hline Agriculture labour & 7 & 10.8 & 2 & 3.1 & 1 & 1.5 & 0 & 0.0 & 10 & 15.4 \\
\hline Coolie & 10 & 15.4 & 5 & 7.7 & 2 & 3.1 & 0 & 0.0 & 17 & 26.2 \\
\hline Unemployed & 8 & 12.3 & 4 & 6.2 & 1 & 1.5 & 1 & 1.5 & 14 & 21.5 \\
\hline \multirow[t]{2}{*}{ Total (1) } & 43 & 66.2 & 14 & 21.5 & 5 & 7.7 & 3 & 4.6 & 65 & 100.0 \\
\hline & \multicolumn{10}{|c|}{ Private hospital } \\
\hline Government/ public & 2 & 3.6 & 0 & 0.0 & 0 & 0.0 & 4 & 7.3 & 6 & 10.9 \\
\hline Private sector & 6 & 10.9 & 1 & 1.8 & 0 & 0.0 & 4 & 7.3 & 11 & 20.0 \\
\hline Business & 2 & 3.6 & 4 & 7.3 & 0 & 0.0 & 4 & 7.3 & 10 & 18.2 \\
\hline Agriculture labour & 0 & 0.0 & 1 & 1.8 & 1 & 1.8 & 2 & 3.6 & 4 & 7.3 \\
\hline Coolie & 4 & 7.3 & 4 & 7.3 & 0 & 0.0 & 5 & 9.1 & 13 & 23.6 \\
\hline Unemployed & 9 & 16.4 & 1 & 1.8 & 0 & 0.0 & 1 & 1.8 & 11 & 20.0 \\
\hline Total (2) & 23 & 41.8 & 11 & 20.0 & 1 & 1.8 & 20 & 36.4 & 55 & 100.0 \\
\hline
\end{tabular}

Source: Field data

In the case of private hospital the above table shows that (i) $7.3 \%$ respondents take public jobs and they spend more than Rs 10000, (ii) $10.9 \%$ take a job in private sector and they spend under Rs 4000, (iii) 3.6\% are agriculture labour and they spend more than Rs 10000, (iv) $9.1 \%$ under take 
job as coolie and they spend more than Rs 10000, and (v) 16.4\% respondents are unemployed and they spend below Rs 4000. It is quite interesting that business men are spending more for treatment in government hospitals whereas, coolie workers are incurred more money for treatment in private hospitals.

\section{Concluding Remarks}

The study revealed that the private hospital has provided good facilities compared to government hospital, but the private hospital is more expensive as compared to the government hospital. Other main results of this study are represented as follows:

- There is a positive association between costs of treatment and type of health care facility preferred. The cost of treatment in private hospital is more expensive as compared to the government hospital. The healthcare expenditure is indirectly related to the income of the respondents.

- The major reason for selection of healthcare services by respondents utilizing government hospital were specifically free service and less expensive than those utilizing private hospital respondents.

- The main intention in selection of hospital is especially nearing to the residence and the reputation of the hospital;

- Age, education and income have a negative impact on the healthcare expenditure of users of the government and private hospital. The service provided by the government hospital is not satisfied by the respondents. The private hospital provides good service delivery, but the cost is not affordable to all sections of the society.

This study suggests that there should be available, equity and quality of health care services, which will ensure basic care to the poor and the marginalized for protecting them against ill health and exploitation.

\section{References}

[1] Anbori Ali,Sirajoon Noor Ghani, HematramYadev, AquilMuhammedDaha, (2010).Patient satisfaction and loyalty to the private hospital in Sanaia, Yemen.International Journal for Quality in Healthcare, 22 (4), 310-315.

[2] CahaHavva, (2007).Service quality in private hospitals in Turkey.Journal of Economics and Social Research, 9 (1), 55-59.

[3] Government of Kerala, Directorate of Health Services, (2014).Prepared by Health Information Cell, DHS, Tiruvanthapuram. www.dhs.kerala.gov.in, retrieved on 5/4/2016

[4] Government of Kerala, Health policy, (2013). www.dhs.kerala.gov.in, retrieved on 5/4/2016

[5] Irfan Syed Muhammad, AamirIjaz, SamanShabbaz, (2011). As assessment of service quality of private hospitals in Pakistan: A patient perspective, Indian Journal of Commerce and Management Studies, 2 (2), 20-30.

[6] KarekarPrashant, AparnaTiwari, SakshamAgrawal, (2015). Comparison of service quality between private and government hospitals: An empirical evidence from Yavatmal city, Maharashtra.International Journal of Advance Research in Computer Science and management studies, 3 (6), 39-43.

[7] KaushikKrishan K, Kurt K. Klein and Lawrence N. Arbensar, (2006). The Relationship between Health Status and Health Care Expenditure in a Developing Hill Economy: An Econometric Approach.The Indian Economic Association, and 89th IEA Annual Conference Volume. 
[8] Kayral Ibrahim H, (2014). Perceived service quality in healthcare organizations and a research in Ankara by hospital type, Journal of Ankara Studies, 2 (1), 22-34.

[9] Kumar Chandanand and Ravi Prakash, (2011).Public private dichotomy in utilization of health service India.consilience: The Journal of Sustainable Development, 5 (1) 25-52.

[10] Mukhopadhyay, Debes, (2006). The Private Health Sector in India-Tryst with Dispute.The Indian Economic Association, 89 ${ }^{\text {th }}$ Annual Conference Volume.http://www.worldcat.org/title/economicsof-education-and-health-in-india/oclc/190760934. Date Accessed: 25/01/2017.

[11] Raman Kutty V., (2000).Historical Analysis of the Development of HealthCare Facilities in Kerala State, India.Health Policy and Planning, 15(1), 103-109

[12] Reddy K., N., (1994). Cost of health care: A household survey in an Indian District, foundation for research in community health Mumbai.

[13] Saish B G and Manjunath S., J., (2010).Corporatization of Health care sector in India, Southern Economist, 48 (24), 49-51.

[14] Shankar Prinja, Maninder Kumar, Andrew D, Pinto, Stephen Jan and Rajesh Kumar, (2013).Equity in Hospital Service Utilization in India.Economic and Political Weekly, March XL7 (12), 52-58.

[15] Shyni M., C., (2015). A case study on the development of healthcare facilities in Kerala.International Journal of Management and Social Science Research (IJMSS), 4 (7), 74-78.

[16] Singh Narinder Deep., (2010). Rural Healthcare and Indebtedness in Punjab.Economic and Political Weekly. 45(1), 22-25.

[17] WHO, (1948).The World health report 2004, changes history WHO, Geneva.

[18] World Health Organization, (1979).Global strategy for Health for all by the Year 2000, Health for all series 2, Geneva.

[19] ZaimHalil, NizamettinBayyurt and SelimZaim, (2010).Service quality and determinants of customers Satisfaction in hospitals: Turkish Experience.International Business and Economic Research Journal, 9(5), 51-58.

\footnotetext{
*Corresponding author.

E-mail address: maneeshpanakkee121@gmail.com
} 